\title{
Approaches to the Management and Policing of Food Safety: The Food Standard Agency's Regulating Our Future
}

Richard Bradford-Knox ${ }^{1}$ Kevin Kane ${ }^{2}$, Simon Neighbour ${ }^{3}$ RBK Consultants, United Kingdom University of Salford, United Kingdom Preston City Council, United Kingdom

\begin{abstract}
This paper forms part of an ongoing project studying various approaches to the management of hazards and risk in the food industry with implications for other areas of risk management where cooperation and collaboration between organisations are of a potential benefit. In this paper we give particular focus to the Food Standard Agency's proposed Regulating Our Future that requires closer cooperation and collaboration between the public enforcement authorities and the industry organisations that police food hygiene and food safety management. The forming of a Primary Authority between Cornwall Council and Safe and Local Supplier Approval (SALSA) emerged as a potential means of contributing to this by improving trust between all parties involved, sharing of information, assessing risk, reducing inspection times and frequency of inspections from Primary Authority. Attention is given to the current relationship between the various organisations involved from the perspectives and viewpoints of Local Authority Enforcement Officers from Preston City Council, Cornwall Council and SALSA and other experienced food safety professionals. The research is qualitative and grounded, including a review of the extant literature and interviews with food safety and food standards professionals from the private and public enforcement sectors.
\end{abstract}

Keywords: Cooperation; Collaboration; Trust; Risk Management; Compliance; Food Standard Agency; Food Safety

Received: 25 April 2020

ISSN 2056-757X

Revised: 12 May 2020

Accepted: 26 May 2020

https://doi.org/10.18646/2056.72.20-012 


\section{Introduction}

It is the view of the Institute of Food Science and Technology (IFST) (IFST 2019) and their response to DEFRA's National Food Strategy consultation (DEFRA 2019) that a paradigm shift in behaviour across food system actors and stakeholders is needed to establish the level of collaboration and cooperation required to deliver an effective UK Food Strategy. Support for sustainable farming and food processing and the delivery of safe, sustainable food for the UK should be on everyone's agenda. A forum to facilitate this new way of working would provide balance and consistency across policy, positions, and communications (IFST 2019).

The Food Standards Agency (FSA), a non-ministerial part of the UK Central Government, recognises the need for improvement in the way they deliver regulatory assurance and has launched a project named "Regulating Our Future" (Food Standards Agency, 2018). With a target date for implementation of 2020 the intention of the project is not to change existing regulations but is described in the opening statement of the document entitled 'Regulating Our Future - Why food regulations need to change and how we intend to do it'. They declare: "It is important to say that this is about how we deliver regulatory assurance; it is not about changing the actual regulations that specify what businesses are required to do" (Food Standards Agency, 2017 c, p. 3). The intention is to improve delivery of controls across the food chain, including those for animal feed, by prioritising improvement where there has been no modernisation of the system in recent years and where it is most needed (Food Standards Agency, 2018).

This research is limited to the relationships between food manufacturing businesses, private auditing bodies, the FSA and Local Authorities (LAs). It does not cover relationships and interventions with catering and retail food businesses. The research includes the ongoing formation of a coordinated partnership between SALSA and Cornwall Council to form a Primary Authority partnership and the possible ways other food industry auditing and private certification bodies could contribute to improved cooperation or working in partnerships with public enforcement bodies. The research conducted includes a review of the extant literature and interviews with food safety and food standards professionals from the private and public enforcement sectors.

\subsection{Benefits of Improved Cooperation}

As proposed by Kleboth et al (2016) a new paradigm in risk-based auditing is needed that acknowledges the behaviour of complex systems to ensure trust along the food chain.

Currently when retailers and suppliers vet or approve their suppliers they usually rely on some form of evidence that they are certified or approved by a recognised body such as the Food Standard Agency (FSA, 2017a) and local government inspections. While this gives them a degree of assurance that the food businesses produce is safe and fit for consumption it does not enable them to access detailed audit or inspections reports. Being able to do so would potentially give the buyers increased assurance that the audit(s) and the standard(s) applied adequately covers their own particular

International Journal of Management and Applied Research, 2020, Vol. 7, No. 2 
concerns, standards, particular areas of interest, good hygiene practice and that appropriate corrective actions have been taken to control hazards and reduce risks.

If their concerns have not been met or covered they can take appropriate action. For example, arrange their own audit or inspection or request further reassurance and evidence from the supplier or local authority. If such a system can be put in place throughout the food industry it has the potential to result in safer food for consumers, and economic savings for all parties. Not just in the cost of audits themselves but also in the cost of time and audit preparation which can be significant (Bradford-Knox 2017).

\section{Regulation and Food Safety Incidents}

Some very serious incidents resulting in illness and sometimes death have come to the public attention over the last two decades. These include the horsemeat scandal (BBC News 2013), E.coli outbreak in South Wales (Gibbons, 2005) and mad cow disease (BBC News, 2018). These incidents and outbreaks suggest that improvement in food safety controls including auditing and inspection need to be continually reviewed and improved (Beck et al., 2005).

Having similar concerns, The U.S. Food Safety Modernization Act (Fortin, 2015) has been developed to modernize the laws in U.SA. and to meet the food safety challenges and complexities of the increased globalization of food supply and the risks presented by longer supply chains that make identifying a weak link more difficult.

Among the FSA's reasons for change is that they view the existing approach as a 'One Size Fits all' and regard that as being ill suited to the current diverse nature of the food industry which has seen large numbers of new players enter the global food and food safety landscape; for example, online retailers, food delivery services and private auditors. They further claim that many of these developments have created different risks, reduced, and increased risks and that the system is 'clunky' rather than flexible and agile.

Further claims of the ROF seek to reduce the regulatory burden on business. It suggests that appropriately trained and competent auditors will be able to inspect/audit businesses and pass the results of their audits to Local Authorities (LAs), who would then use the information to calculate an inspection risk rating - the frequency of inspection - but also their food hygiene rating (Bradford-Knox and Neighbour, 2017).

The following views are expressed in an interview with Simon Neighbour (Environmental Health Manager and co-author) and reflected by Professor Liza Ackerley at Chartered Institute of Environmental Health (CIEH) national conference (Hatchett, 2017).

The Environmental Health Profession (EHP) has concerns over this approach - or rather, the professionals employed in Local Government do. Recent years have seen an increasing number of Environmental Health Practitioners employed in the private

International Journal of Management and Applied Research, 2020, Vol. 7, No. 2 
sector, and so the voice of the profession is no longer the preserve of Local Authority EHP's, but rather a wider spread of views.

We suspect there will be some differences in the views the two groups over what those in LA employments see yet another route to self-regulation. Broadly, LA EHPs would prefer independent regulation.

Professor Liza Ackerley at a CIEH annual food safety conference (Hatchett, 2017) called for a single food safety assurance scheme that everyone can join in with. Proposing a radically simplified national scheme, she said:

"Businesses don't want someone going in and waving a great big stick and then someone else going in and doing a 'good cop bad cop' thing, so the visit they get, whether it's from a local authority or a private sector auditor, needs to help them to get to the place where they need to be" (cited by Hatchett, 2017).

She said that her proposed not-for-profit scheme, covering the catering sector only, would involve a centrally held database (Hatchett, 2017). Local authorities would be able to view relevant parts of the database, but, because it was not held in the public domain, it would not be subject to freedom of information requests. The central body holding the database would work with stakeholders to set standards and competencies for auditors, including training requirements (Food Standards Agency, 2017c). But it would not be compulsory for auditors to join the scheme.

She reassured her audience and according to her, under the new system, local authorities would still be responsible for enforcement activity, including awarding food hygiene ratings and re-ratings. But, in some cases, it would be informed by data from external auditors.

"Local authorities would be doing exactly as they were before, but they would have access to a lot more information from more sources and they would be able to consider it as part of the whole picture in relation to food businesses" (cited by Hatchett, 2017).

The new paid-for service would be based on the British Hospitality Association's Catering Guide, with reference to Annex 5 Food Standard's Agency's food law code of practice. She argued that it would simply regularise what is already happening in the marketplace, with businesses receiving advice, guidance and coaching from many bodies but that it would give added value and public reassurance to the businesses signing up (Hatchett, 2017). Small businesses that do not currently receive many inspections from EHOs would benefit (Bradford-Knox and Neighbour, 2018).

Giving the example of SALSA (Bradford-Knox and Kane, 2014) as an effective existing accreditation scheme, she said:

"We want to make sure that the scheme is not difficult or expensive for anyone to join, that it would have transparent governance and that it would enjoy the trust of consumers and local authorities" (cited by Hatchett, 2017).

International Journal of Management and Applied Research, 2020, Vol. 7, No. 2 
The last comment about SALSA is interesting in that SALSA currently only covers food manufacturers and not catering or retail establishments. Potentially it could be adapted, follow its present principles of being, not for profit, user friendly and providing much support guidance and training (Bradford-Knox et al., 2016).

It has developed to cover different food sectors that have unique or different technical processes or standards of practice that are required by the manufacturers and customers. These include cheese manufacturing, breweries, organic foods and together with STS those supplying vulnerable people in the public health sector. Another advantage of SALSA is that unlike other food safety auditing standards, SALSA auditors are allowed to give advice and guidance during the audit process (SALSA 2011), rather than just making a list of non-conformances (Bradford-Knox and Kane 2014).

Since the start of this research SALSA have formed a Coordinated Primary Authority Partnership with Cornwall Council (Business Regulatory Support, 2019) that can potentially fulfil one of the ROF objectives of sharing audit information and adding credibility to the SALSA standard.

\section{Auditing and Inspections}

Regulating and managing food safety using audits and inspections are key to managing and regulating food safety by both private, government and food industry bodies. Audit systems, in their current form, have limitations in improving food safety and there is a long and storied history of food safety failures involving third party audits and inspections (Powell et al. 2013).

Food safety and quality audits and inspections are used widely in the food industry to evaluate management systems, obtain certifications to certain food safety and quality standards, and confirm legal compliance. These standards have both advantages and disadvantages and their effectiveness depends on several factors including the competency and skills of auditors and the standard used in each case. The number of foodborne outbreaks per year appears to be quite stable (but have not reduced) in both Europe and the United States. This may be an indication that additional measures and techniques or a different approach are required to further improve the effectiveness of the food safety and quality management systems (Kotsanopoulos et al., 2017).

In the view of the Food Standards Agency the prime reasons for governmental inspections and audits as described in the ROF are to ensure that food business meet legal regulatory requirements (Food Standards Agency, 2017c). The reasons for private or food industry audits carried out by the various bodies like the British Retail Corporation, major retailers and those that have special interests or requirements in standards of food differ in that are not limited to food hygiene and food safety legal standards. They are based on their own requirements for best practice, quality and 'special interests' (Bradford-Knox \& Neighbour 2018). For example, The Soil Association (2017) is concerned with 'Organic Foods' while Red Tractor (2020) claims to ensure the food is traceable, safe to eat and has been produced responsibly. This includes animal welfare, food safety, traceability, and environmental protection.

International Journal of Management and Applied Research, 2020, Vol. 7, No. 2 
Their logo indicates and is restricted to food has been farmed, processed, and packed in the UK.

The frequency and number audits and inspections in the food manufacturing sector, unlike inspections carried out by local government, are not risk based (BradfordKnox, 2017). In the private sector the frequency of audits carried out over a predetermined time period is not based on the hazards and level of risk associated with the type of food or the process being carried out. Rather, the frequency and numbers of audits and inspections appears to be based on custom and practice, i.e. The annual auditing of food premises is the common norm.

This appears to contradict the principle and legal requirement that the food safety management of food premises must be risked based as per Article 5 of Regulation (EC) No 852/2004. In our view, as part of the management of and control of food hygiene of the food chain, auditing and inspections need to achieve a frequency of auditing and inspection that is effective enough to ensure a consistent level of compliance and improvement in standards that ensures food is safe for consumption.

The number and frequency of audits and inspections are also driven by the following factors (Bradford-Knox, 2017):

1. The customer base: The number of customers a business has, who they supply, and whether they are required to meet certain specialist areas of supply and claims made about their products (e.g. gluten free, organic, or religious requirements).

2. Trust issue: A lack of trust between auditing bodies and inspectors in the integrity of audits and inspections carried out by, and on behalf of, other retailers, other auditing bodies and public enforcement bodies. The FSA Summary Report of the Pilot Project on the Potential for Recognition of the BRC Global Standard for Food Safety (Robinson, 2017) explores the potential of an Earned Recognition (ER) scheme for food hygiene and food standards official controls for establishments certificated under the BRC Global Standard for Food Safety that is described as 'a private assurance body.' The report points out that ROF is moving away from ER to 'regulated private assurance'. Views were obtained from food hygiene and food standards Competent Authority (CA) officers and FSA assessors. There were mixed opinions among these assessors. They did find significant commonality between BRC audits and CA inspections but there was a perceived difference in purpose, focus and approach. In their view, the main difference was the purpose. Finding BRC to be focussed on the compliance against their standard and CA inspections focussed on assessment of risk to public health. However, there was general acceptance that BRC audit reports could be used to help inform the frequency and/or focus of CA interventions.

3. Economic and Commercial Factors: The cost of auditing can be high for those paying for the audits and inspection. This can be the buyers of the products or raw materials and/ or the retail suppliers. The latter being the most common. In the case of the various government bodies that bear the cost the number of audits or inspections can be limited by their budgets.

International Journal of Management and Applied Research, 2020, Vol. 7, No. 2 
4. Audit Effectiveness: The view of many professional auditors is that unannounced visits keep businesses 'audit ready' at all times. If this is true, then the frequency of visits and therefore duplication of effort can be reduced. Further duplication of effort and cost can also be averted if an audit or inspection has been carried out recently by a universally recognised body. This approach would entail recognition of the integrity of the many auditing bodies and the exchange of information between them. It would necessitate providing and sharing audit reports between audit bodies, suppliers and buyers. This in turn would enable, all parties concerned to be aware of the strengths and weaknesses, special circumstances or interests covered by the audit(s). From this information a judgment can, be made whether a further audit or audits are necessary on order to approve a supplier (Bradford-Knox and Neighbour, 2018).

\section{Risk assessment of audit frequency: local government inspections}

A system of determining the frequency of audits already exists as described in the FSA's Food Law Code of Practice (FSA, 2017a) for determining the frequency local authority inspections. This is performed by identifying a number of risk criteria and allocating points against each one according to the perceived level of risk each one presents. The higher the points, the higher the risk, and thus the greater need for more frequent inspections.

The criteria extracted and summarized from the Food Law Code of Practice are:

1. Type of food and method of handling.

2. Method of processing method (low/high risk).

3. Consumers at risk (local, national, international).

4. Level of (current) compliance. (Food Hygiene Performance)

5. Condition of Structure.

6. Confidence in management/control procedures.

7. Where the production of or the service of high-risk foods take place to the vulnerable e.g. hospitals, care homes and children's nurseries.

\section{Methods and Methodology}

A grounded qualitative methodology was used by interviewing focus groups and individuals with first- hand experience of Local Authority inspections and food safety enforcement. This was supported by a review of the extant literature, and empirical evidence. All interviews were conducted using semi structured questions to elicit personal and group viewpoints.

The use of grounded theory method led to the inclusion of Cornwall Council following the interview with SALSA when the Primary Authority between both parties emerged. All interviews were recorded, and transcribed and analysed using qualitative methods.

Four groups of people were interviewed consisting of:

1. Four Environmental Health Officers (EHOs) from Preston City Council,

International Journal of Management and Applied Research, 2020, Vol. 7, No. 2 
2. An Independent Food Safety Consultant and an ex-EHO and Production Manager of a meat processing company in Bolton

3. A Business Development Manager from SALSA.

4. Cornwall Council/ SALSA Lead Environmental Health Officer, Primary Authority Account Manager and Business Development Manager representing SALSA.

\section{Results}

\subsection{Summary of Preston City Council Focus Group (April 2018, 4 attendees)}

Group led by Simon Neighbour (SN), a Senior Environmental Health Manager.

SN Intro: To have a sharing of views around the Food Standard's Agency's Regulating Our Futures (ROF) proposals even though they have changed substantially since they were introduced and as the FSA tell us this is open policy making and undoubtedly there will be further changes as time goes on.

Question 1: Is the way we operate in line with current the Food Law Code of Practice?

Responses: The only difference we have is that when a premises scores worse than $10,10,10$; we score them on a 12-month intervention frequency rather than 18 months. When this is a little bit worse if it is $10,15,10$ code of practice says that then that would be 18 months. We do them every 12 months. If a premise is non-compliant we inspect them more frequently than the code of practice but other than that, in his view, they are pretty well much compliant with the code of practice.

Question 2: Are the risk rating criteria the food law code of practice broadly right?

$\mathrm{SN}$ : In terms in the way it is set out it is not only the inherent major risk that the premises operate at. You get a score of 30 for handling High Risk Food but you get a lower score if you are handling low risk package stuff. You also get stuff processing food, you also got stuff on customers at risk, before you get into issues around structure, hygiene and code of practice.

Responses: Group broadly agreed but there are grey areas where one thing merges from one to another. If you give a low score in one aspect you should not consider it in another. Example if someone's hygiene practices are not very good you should not consider that as part of the confidence in management, but we think it is not as clear as it could be.

SN: The FSA Brand Standard (FSA, 2017b) gives information which is not quite lined up with the Food Law Code of Practice (FSA, 2017a).

General agreement of the group.

SN: It does not always line up with established custom and practice.

Example given by group: If there is a risk of E.coli 157 or other VTEC it goes in the risk rating. The score goes up making the risk higher and the premises get inspected more often .This is not represented in the Brand Standard for the actual Food Hygiene Rating Scheme (FHRS) seems short sighted because you can have 2 premises that

International Journal of Management and Applied Research, 2020, Vol. 7, No. 2 
score the same except one has the risk of E.coli but they have the same rating for everything else.

Further discussion ensued regarding risk rating that implied that the group considers there a need to clarify and or revise the risk rating scheme in relation to the frequency of inspections and further implies that there can be different interpretations of requirements by Environmental Health Officers.

SN pointed out that the inspection frequencies scheme established the longest time you can leave between inspections. You can always go back more often.

There was a discussion among the group about inconsistencies and a general view that inspections are 'not always going to be consistent across departments, businesses, districts and individuals.

From the general discussion it emerged that there is a lack of trust by the focus group of BRC and SALSA auditors and by implication the private or industry standards. Some of the group claimed that they had found that quite a lot of information had been missed by BRC/SALSA auditors and that there may be a lack food safety training among them and knowledge.

They were also suspicious or rather reluctant to accept everything BRC and SALSA auditors found. In their view the auditors are paid by the food businesses and therefore maybe not independent enough.

SN: Regulating Our Futures is about or partly about using more information that is out there using auditors. I think we as a profession have concerns about how useful that data is and how valid it is.

Group view was that they would like to have the information from other audits but not knowing their background they would not be happy doing food hygiene or risk rating to determine inspection frequency based on their information alone. There was also some concern that private auditors as opposed to government inspectors do not carry out enforcement but as pointed by SN the intention of ROF is that any enforcement will be taken by Local Authorities (LAs). The group wanted to know if private auditors will have a duty to report any breaches of the law to LAs.

\subsubsection{Preston City Council - Follow up meeting}

In response to questions from the lead author SN held a follow up meeting with his group to address the following points from the first meeting.

Question 1: How to overcome lack of trust?

There is a fundamental suspicion that third party auditors may be susceptible to influence from the auditee, given that the auditee is paying for the audit. This is partly on assumptions (and not particularly well thought through ones) but also from officers' own experiences and gossip. In SN view not especially useful sources of information from officers who use evidence based - based reasoning for most of their professional lives!

International Journal of Management and Applied Research, 2020, Vol. 7, No. 2 
Officers recounted instances where they recall middle, senior managers and directors of manufacturing businesses ,expressing opinions about the value of audit reports, when they were 'able to negotiate' their content. This was about agreeing not to include certain observations or minor non-conformities if they could assure the auditors they would be fixed /were being fixed before the end of the audit.

Question 2: How to overcome a lack of trust in other auditors?

In his view SN, based on his experiences of dealing with FSA, he did not see the need to 'overcome a lack of trust on the grounds that the ROF will be what it is and the EHOs will not be able to influence how the FSA deploy it.

Question 3: Would more awareness training be of benefit?

This is in regard to awareness training for EHOs to improve their knowledge and understanding of Third-Party Auditing and Auditors. The group suggested that it would not need to be a training course as such, more like an informal discussion group. This could come with ROF anyway, but informally rather than at the FSA's intent.

Question 4: When and where have private auditors missed contraventions or nonconformances?

The team were all able to recount instances of inspecting premises that 3rd party auditors have 'just visited' (within a month, typically within a week) and found issues that we have been told were not picked up by the auditors. SN recounted his own personal experiences of where auditors had apparently missed non-conformances including where a food business failed to perform monthly reviews.

SN was sure that the same happens from an auditor's point of view, and EHO's probable reply with "I'm only here for a snapshot, point in time inspection and it's not my job to check everything". While LA regulators might have a distorted or inaccurate view of 3rd party auditors he is sure there are similar stories on both sides. His view is that possibly there is an advantage of both groups engaging better, and maybe ROF will deliver that.

Question 5: Enforcement, Improvement and Corrective Action? - Differences in meaning of these terms.

The general consensus of the group was that Enforcement was something a regulator did, with legal powers to require works to be done. Corrective Action was seen very much as an auditing approach where steps needed to be taken to ensure conformity. Improvement seems to apply to both groups - enforcement staff and auditors. The regulators' view is that we are looking for any premises rated below a 5 in Food Hygiene Rating Scheme, and shift from an informal voluntary advice and guidance approach towards a more formal, enforcement based one as ratings drop south of 3 . The same term is felt to describe an adjustment to documented procedures or practices as part of an audit - possibly identified by the auditor, but more likely by the auditee as part of an improvement plan.

6.2. Interview with an independent consultant and a former EHO and Production Manager of a meat processing company (January 2019)

International Journal of Management and Applied Research, 2020, Vol. 7, No. 2 
Interviewee: JH (consultant) and TU (former EHO)

Interviewer: RBK

RBK: Have read about Regulating Our Future?

JH: Yes.

TU: No.

RBK then gave a short description describing the key points about the utilization of information from private or food industry audits together with local authority inspections. If audit reports from BRC or SALSA for example are available time could be saved by reducing the number of inspections carried out by LAs.

RBK: What are your thoughts on what you've read?

$\mathrm{JH}$ : Speaking as an ex EHO from an enforcement perspective and from 5 years acting as a Food Safety Consultant. There will be reluctance from a lot of the enforcement side to this kind of initiative because of human nature. It is self-preservation. They will feel threatened that potentially someone is taking their jobs away. It's the thin edge of the wedge with private industry and whether private industry would be too much embedded with some companies (food businesses). There is a historical belief that an officer going to inspect a premise has no other agenda than applying the law in an impartial way.

Having been on the other side of the fence I can see the benefits of the experience that go into these premises from private auditors. I believe we are all in this together and this is the attitude and culture that should be adopted.

RBK: Part of it appears that LAs have been suffering from a lack of resources. As a result, the number of visits has been restricted.

$\mathrm{JH}$ : It is right to acknowledge this. LAs are short staffed and under resourced. Companies being audited by BRC, SALSA and others are in some respects more in depth that those carried out by LA officers.

RBK: What are your views on increasing and improving cooperation between EHOs, LAs and the private sector in regard to food hygiene inspections and audits?

JH: I think it is incumbent on LAs. They have got to accept that they (private auditors) are there. There are limited resources, so you have to tap into them.

TU: Recently they turn up here every 6 months. The LA officers always complain how busy they are and cannot do a full day audit, so they are a couple of hours here. JH: I think it has pulled everything together. It covers in greater depth than an EHO's visit. EHOs are literally under pressure and will pick just 2 areas for inspection. It could be 2 months before you get the report back from an EHO inspection saying that it needs addressing immediately.

TU: Nobody checks what you have done for another 5 or 6 months afterwards.

RBK: How well do the LAs cooperate with the food industry and vice versa?

$\mathrm{JH}$ and TU: In their experience EHOs are very cooperative, but it varies from officer to officer.

International Journal of Management and Applied Research, 2020, Vol. 7, No. 2 
$\mathrm{JH}$ : You have some officers who are of the tick box mentality . You either comply or you do not comply. Then you have others who - it's a partnership. Phrase I used as an EHO -- "We are in it together" -- I am putting my name to your premises.

JH: Thinks that some EHOs do not really understand risk assessment in a lot of instances. They might know the laws to what section has to comply but not the actual intricacies of food production and what the associated risks and controls are. There is not the depth of knowledge of the bigger food manufacturing premises that consultants might have. When dealing with BRC audited companies he asks to see the report of their last BRC audit. It is like having another pair of eyes. They (BRC Auditors) can see things that I could miss, and I build that into my report.

RBK: What are your views on establishing audits and inspections on the basis of risk as, for example, exemplified in the Food Law Code of Practice?

$\mathrm{JH}$ : I think it is the right approach but what is not taken into account is that the food businesses are being externally audited as well: e.g. by BRC or others. It seems to be a waste of resources not to take those into account.

\subsection{Interviewed with a SALSA Scheme Development Manager (August 2019)}

Interviewee: BJ

Interviewer: RBK

BJ, a SALSA office personnel received an overview of what ROF was going to achieve from the FSA and FSA were sending out regular Newsletters to inform on progress but recently the communication has slowed down over the last few months. Note: This last comment is confirmed by Dinkovski (2019).

Otherwise the FSA appear to be moving ahead with ROF quite quickly with the 'digital stuff and registering businesses online which is a major strand'. SALSA is interested in ROF and becoming more involved in it. They are interested in learning more and think it has great potential.

RBK: There seems to be mistrust between EHOs and private auditors (TPAs) and the audit standards. One question asked of one group of EHOs was "Would they make a risk rating on the basis of private audit?" They were not in favour.

BJ: I have not experienced that directly. Potentially think there is some mistrust. Probably at the heart of that there is a difference of view of what the different organisations are trying to achieve. If a private company has a different set of objectives and a different agenda to a public company. Consider SALSA different because they are not-for-profit organisation and already a collaborative organisation with the founding partners. Can understand why on an individual level people might be nervous about sharing with private companies that have a completely different agenda (refer to FSA report on BRC and earned recognition (Robinson, 2017, See section 2.2).

BJ described difference between SALSA and environmental heath as follows: Food safety standards including SALSA operate for the industry while Environmental Health operates for the public.

International Journal of Management and Applied Research, 2020, Vol. 7, No. 2 
RBK: Is that not the same? Is there scope for more collaboration and partnership between the public and private sectors in food standards and food safety?

BJ: I think there is 'bags of potential' for collaboration. Collaboration involves compromise to some extent but thinks that as an industry we are stronger together. Particularly for the benefit of SMEs and our collaboration with enforcement through Primary Authority should prove that concept. Hopefully, we can expand further. SALSA need to collaborate more effectively and there are lots of different organisations we can do that with and something we can work on.

\subsection{Interview with Cornwall Council and SALSA (December 2019)}

Interviewee: GH from Cornwall Council and BJ from SALSA

Interviewer: RBK

RBK: What are the aims and objectives of forming a coordinated Primary Authority partnership with SALSA?

$\mathrm{GH}$ and BJ: Objectives were similar for both parties. SALSA goes in without any enforcement 'perspective'. SALSA considered it important for SALSA to have 'a stamp of approval' in regard to its meeting enforcement /legal requirements. From Cornwall Council's point of view, they recognised that in some respects the SALSA audit and standard is more comprehensive than an inspection. This is particularly applicable to the SALSA Cheesemakers standard. Note: Cornwall Council also have a Co-ordinated PA with the Specialist Cheesemakers Association (Primary Authority).

GH propose that knowing that a food business has SALSA accreditation can potentially enable enforcement officers to concentrate on "the enforcements requirements" and any advice issued under the PA partnership means that all the relevant steps will have been taken to ensure that the business is aware of all legal requirements and how to implement them. Furthermore, this has the potential to save time on inspections and the timing of forming this PA also seemed right in view of the objectives of ROF.

In order to approve the SALSA standard, Cornwall Council have reviewed the SALSA Standard and suggested some changes to three clauses in order to improve the robustness of the standard. They did not consider that there is anything missing in the standard but in their view sometimes it was not explicit enough about what was being looked at.

At the time of the interview in December 2019 the proposed changes had been sent to SALSA and were being checked and assessed by their Technical Advisory Committee.

The approval process at Cornwall Council follows a very strict procedure: 'Assured Advice' given under a Primary Authority partnership is not delivered by a single officer in isolation. All Assured Advice issued goes through a process of internal peer review delivered by a team of officers who are considered to be competent to assess the validity of any advice being delivered. Many of these officers sit on the Council's Internal Approved premises committee which is a panel of experiences officers with robust knowledge of food safety matters.

International Journal of Management and Applied Research, 2020, Vol. 7, No. 2 
RBK: Would you take a company having SALSA into account when setting your frequency of inspections?

GH: That will be very much in the hands of the FSA because they are the people responsible for the Food Code Law of Practice. When we inspect any business whether approved or not we have a list of criteria that we have got to rate them on. However good they are, we can't reduce their frequency of inspection and if they are supplying the whole of the country that throws them up into a higher risk band. The only way that can change would be if the FSA re looked at the Food law code of practice and maybe tweaked it so we could reduce the number of interventions made (FSA, 2017a).

RBK: What level of trust as enforcement officers do you have in the integrity of private audits like BRC? SALSA we have already discussed. There are STS, TESCO and $M \& S$ who have got their own and so on?

GH: They have much discussion around conflicts of interest in Cornwall. Some officers are sceptical about the lack of transparency and visibility and this can lead to scepticism about the quality of the audits carried out.

GH: We are at the stage of assuring the SALSA standard itself and the next step will be to actually assure the selection process of the auditors themselves.

RBK: How can Cornwall Council improve cooperation and collaboration between public and private, industrial auditing bodies and standards be improved?

$\mathrm{GH}$ : It is around trust and transparency. We have to demonstrate transparency on our side. We are asked to do that and periodically we do have to justify our decisions being made. It links into the trust element of the relationship between the coordinated partnership, the coordinator and Cornwall council and the organisations that are doing the auditing and having those impacts with being transparent about their processes, how people are appointed and what their qualifications and competencies are. If we can publish something around that on the PA register that will give the enforcement officers increased confidence.

RBK: What about the partnership and your view SALSA as an organisation?

$\mathrm{GH}$ and BJ: For PA to work the LA has got to have great integrity but equally as much I would say the actual business itself we are representing, the organisation, we need commitment from them. If there is no commitment the PA will not work. To date the commitment from SALSA has been brilliant.

\section{Discussion}

One of the main stumbling blocks in implementing the ROF appears to be the level of mistrust by EHOs of Third-Party Auditors (TPAs) and between the various retailers of each other's audit standards. This could jeopardise the efficacy of ROF.

This lack of confidence or trust in the integrity does not appear from the interviews to be founded on evidence. Third Party Auditing Bodies and Certification Bodies are accredited by The United Kingdom Accreditation Service (UKAS) the sole national accreditation body for the United Kingdom. UKAS is recognised by government, to

International Journal of Management and Applied Research, 2020, Vol. 7, No. 2 
assess against internationally agreed standards, organisations that provide certification, testing, inspection, and calibration services. Nevertheless, a suspicion exists by EHOs at Preston City Council that because Third Party Auditors are paid by the companies they audit they may be not be 'independent enough'. The Preston group also claimed that they had found things that had been missed by the TPAs thereby throwing doubt on the competence of the TPAs. As part of their co-ordinated Primary Authority agreement with SALSA Cornwall Council (Primary Authority) have reviewed the standard to ensure it is robust and meets regulatory requirements and made a number of recommendations. However, they report some lack of confidence exists in the competence and qualifications of private or food industry auditors.

This is in spite of the requirement for all SALSA auditors being required to register with Institute of Food Science and Technology (IFST) and to maintain their registration through Continuous Professional Development (CPD) (IFST, 2019 b).

BRC-FSA (2017) showed that there is some misunderstanding amongst CAs of the BRC standard and suggest that this could be addressed by an awareness and training programme for CAs and we suggest that this could also be applied to all enforcement officers in regard to 'private audits and standards '.

However, as stated by SN and Cornwall Council it is not something Local Authorities have control over. LAs will do whatever the FSA demand of them.

JH an ex EHO with 37 years' experience has a more positive view (See Section 5.2). He has found that audit reports by TPAs had been of help in his work and that not to use them in risk assessing inspection or audit frequency is a waste of resources and that the distrust expressed was based on self-preservation by the EHOs.

Whatever the reasons it is our view that it is a matter that must be overcome if the proposals of ROF are to work and that all parties can benefit.

SALSA's integrity and continuity is already assured in that it answers to an independent body of governors, is non-profit making, all SALSA auditors are registered and accredited by the Institute of Food Science \& Technology (SALSA, 2011). Certification is performed in house by its own personnel and not by separate certification bodies. This is not to say that other certification bodies that are accredited by United Kingdom Accreditation Service (UKAS) lack professionalism, but with so many different bodies there is a potential risk of losing continuity in maintaining the level of applicable standards.

\section{Conclusion}

We propose that the current situation can result in one of two outcomes. Firstly, that there is a risk that many higher risk businesses are not audited as frequently as they should be and conversely that many lower risk businesses are audited or inspected more frequently than is necessary. It can also be argued that having a variety of different types of audit or inspection may give 'better coverage' and help to ensure

International Journal of Management and Applied Research, 2020, Vol. 7, No. 2 
that all aspects of food hygiene and food safety are addressed and more likely that any weaknesses exposed. It may be also the view of some that a high frequency of audits can only be desirable and potentially ensures safer food for consumers. As Powell et al (2013) point out audits and inspections are 'snapshots' in time. This implies that more frequent audits can provide more than one snapshot and therefore provide a fuller picture over time of food hygiene and food safety standards.

As noted in Section 2 of the 'Summary Report of the Pilot Project on the Potential for Recognition of the BRC Global Standard for Food Safety' (Robinson, 2017) the CA enforcers perceived a difference of purpose. Finding BRC to be focussed on the compliance against their standard and CA inspections focussed on assessment of risk to public health. Because both approaches are risk based there does not appear to be a significant difference in the ultimate aims and objectives of both public health inspectors and private standards. The main purpose and objectives of both parties is to ensure to ensure that food is safe for public consumption. What is significant is how well informed and thoroughly inspections and audits are performed and the frequency of them in relation to risk.

In regard to attitudes and subsequent behaviour as suggested by Cornwall Council forming Primary Authorities with law enforcement bodies i.e. Local Authorities, the FSA, and private or food industry standards is potentially a way forward and can result in increased confidence among enforcement officers, and better utilization of the resources of all parties. A lack or shortage of human and financial resources being, in the opinion Simon Neighbour of Preston City Council, is currently the main problem in maintaining appropriate levels of enforcement.

\section{References}

1. BBC News (2013), Horsemeat Scandal [Online] Available from: https://www.bbc.co.uk/news/uk-21335872 [Accessed 20 December 2019].

2. BBC News (2018), Mad cow disease: what is BSE? [Online] Available from: https://www.bbc.co.uk/news/uk-45906585 [Accessed 2 December 2019].

3. Beck, M.; Asenova, D.; and Dickson, G. (2005), "Public Administration, Science and Risk Assessment: A Case Study of the U.K. Bovine Spongiform Encephalopathy Crisis", Public Administration Review, Vol. 65, No. 4, pp. 396408. https://doi.org/10.1111/j.1540-6210.2005.00467.x

4. Bradford-Knox,R., (2017), "Approaches to and the management of the audit process in the food industry", British Food Journal, Vol. 119, No. 4, pp.759-770, https://doi.org/10.1108/BFJ-10-2016-0484

5. Bradford-Knox, R. and Kane, K. (2014), "Safe and Local Supplier Approval - A case study of the third party supplier approval scheme for micro and small food businesses", International Journal of Management and Applied Research, Vol. 1, No. 1, pp. 30-47. https://doi.org/10.18646/2056.11.14-003

International Journal of Management and Applied Research, 2020, Vol. 7, No. 2 
6. Bradford-Knox, R.; Kane, K. and Neighbour, S.(2016), “Approaches to Food Safety Hazard Control and Risk Management: A Case Study of Preston City Council's Food Safety Compliance Strategy", International Journal of Management and Applied Research, Vol. 3, No. 1, pp. 14-29. https://doi.org/10.18646/2056.31.16-002

7. Bradford-Knox, R. and Neighbour, S. (2017), "Food safety compliance approaches: Case study of a primary authority partnership between E.H. Booths Ltd and Preston City Council", British Food Journal, Vol. 119, No. 4, pp.744758. https://doi.org/10.1108/BFJ-11-2016-0539

8. Bradford-Knox, R. and Neighbour, S. (2018), "Staying on the safe side", Journal of the Institute of Food Science and Technology, [Online] Available from: www.fstjournal.org/features/32-1/risk-management [Accessed 19 November 2017].

9. Business Regulatory Support (2019), Primary Authority Partnership, [Online] Available from: https://www.businessregulatorysupport.co.uk/our-services/findout-about-what-business-advice-we-can-help-you-with/primary-authoritypartnerships/ [Accessed 19 November 2017].

10. Department for Environment, Food and Rural Affairs (DEFRA) (2019), National Food Strategy consultation: Overview, [Online] Available from: https://consult.defra.gov.uk/agri-food-chain-directorate/national-food-strategycall-for-evidence/ [Accessed 6 December 2019]

11. Hatchett, W. (2017), “Assurance poses no threat to EHOs", Environmental Health News, [Online] Available from: http://www.ehnonline.com/news/article.aspx?id=16813 [Accessed 19th November 2017].

12. Dinkovski, N. (2019), "Confusion as FSA 'pauses' work on business inspections model", Food Manufacture, [Online] Available from: https://www.foodmanufacture.co.uk/Article/2019/08/09/Food-Standards-Agencypauses-work-on-new-food-business-inspectionmodel?utm source=EditorsSpotlight\&utm medium=email\&utm campaign=2019 -08-13\&c=LowgtlWI43U0aqVyT0AbjS8kvmD0Ac63 [Accessed 19 November 2017].

13. Fortin, N. (2015), “The U.S. Food Safety Modernization Act: Implications in Transnational Governance of Food Safety, Food System Sustainability, and the Tension with Free Trade", Duke Environmental Law \& Policy Forum, Vol. 25, No. 2, pp. 313-337.

14. Food Standard Agency (FSA) (2017a), Food Law Code of Practice: England, [Online] Available from: http://fsa.riams.org/connected/UXYpkuExoT [Accessed 4 December 2017].

International Journal of Management and Applied Research, 2020, Vol. 7, No. 2 
15. Food Standard Agency (FSA) (2017b), The Food Hygiene Rating Scheme: Guidance for local authorities on implementation and operation - the Brand Standard, [Online] Available from: https://www.food.gov.uk/sites/default/files/media/document/fhrs-brand-standardsguide 2017.pdf [Accessed 31 October 2018].

16. Food Standard Agency (FSA) (2017c) Regulating Our Future: Why Food Regulations Need to change and how we are going to do it. [Online] Available from: https://www.food.gov.uk/sites/default/files/media/document/rof-paperjuly2017_0.pdf [Accessed 10 May 2020].

17. Food Standard Agency (FSA) (2018), Regulating Our Future, [Online] Available from: https://www.food.gov.uk/about-us/regulating-our-future [Accessed 31 October 2018].

18. Gibbons, B. (2005), E.Coli Outbreak in South Wales - an update, [Online] Available from: https://www.wales.nhs.uk/news/3895 [Accessed 31 October 2018].

19. IFST (2019), IFST responds to DEFRA consultation on National Food Strategy, [Online] Available from: https://www.ifst.org/news/ifst-responds-defraconsultation-national-food-strategy [Accessed 7 December 2019].

20. Kleboth J.A.; Luning P.A. and Fogliano V. (2016), "Risk-based integrity audits in the food chain - A framework for complex systems", Trends in Food Science and Technology, Vol. 56, pp. 167-174. https://doi.org/10.1016/j.tifs.2016.07.010

21. Kotsanopoulos, K. V. and Arvanitoyannis, I. S. (2017), "The Role of Auditing, Food Safety, and Food Quality Standards in the Food Industry: A Review", Comprehensive Reviews in Food Science and Food Safety, Vol. 16, No. 5, pp. 760-775. https://doi.org/10.1111/1541-4337.12293

22. Powell, D.A.; Erdozain, S.; Dodd, D.; Costa, R.; Morley, K. and Chapman, B. J. (2013), "Audits and inspections are never enough: A critique to enhance food safety", Food Control, Vol. 30, No. 2, pp. 686-691. https://doi.org/10.1016/j.foodcont.2012.07.044

23. Red Tractor (2017), Traceable, Safe \& Farmed With Care, [Online] Available from: https://www.redtractor.org.uk/ [Accessed 12th November 2017].

24. Regulation (EC) No 853/2004 of the European Parliament and of the Council of laying down specific hygiene rules for food of animal origin, Official Journal of the European Union, 29 April 2004, L 139/55, pp. 55-205.

25. Robinson, Y. (2017) Summary Report of the Pilot Project on the Potential for Recognition of the BRC Global Standard for Food Safety, UK: Food Standards Agency, [Online] Available from:

International Journal of Management and Applied Research, 2020, Vol. 7, No. 2 
https://www.food.gov.uk/sites/default/files/media/document/fsa-brc-reportoct17 0.pdf [Accessed 2 December 2019].

26. Safe and Local Supplier Approval (SALSA) (2011), Auditing for SALSA, [Online] Available from: https://www.salsafood.co.uk/am.php?p=2 [Accessed 2 December 2019].

27. Soil Association (2017), What are Organic Standards? [Online] Available from: https://www.soilassociation.org/what-we-do/organic-standards/ [Accessed 29th November 2017]. 